\title{
Utilization of a New Methodology on Performance Measurements of Red Light Violations Detection Systems
}

\author{
Metin Mutlu Aydin ${ }^{a}$, Sevil Kofteci ${ }^{b^{*}}$, Kadir Akgol $^{c}$ and Mehmet Sinan Yildirim ${ }^{d}$ \\ ${ }^{a, b, c}$ Akdeniz University, Civil Engineering Department, Antalya, TURKEY \\ ${ }^{d}$ Celal Bayar University, Civil Engineering Department, Manisa, TURKEY \\ *E-mail address: skofteci@akdeniz.edu.tr
}

Received date: February 2017

\begin{abstract}
In recent years, intelligent transportation systems are under a continuous development which are the direct integration of the technology and traffic engineering aspects. These systems are extensively used in order to prevent driving at high speeds and violations of the traffic rules at different road sections, signalized and unsignalized intersections. These systems have capabilities of detecting the instantaneous and average speeds of vehicles along a roadway section, and red light violations. By the help of these sophisticated systems, road and security authorities can successfully carry out criminal sanctions against non-compliant drivers combined with plate reader cameras. In Turkey, these systems are called Traffic Electronic Control System (TECS) and they are considered under different categories such as intelligent intersection systems, vehicle counting systems, safety strip violation detection systems, speed violation detection systems, speed corridors, red light violation detection systems and parking violation detection systems. Within the scope of this study, the performance of a red light violation system installed at the 4-leg signalized intersection at Antalya-Burdur highway entrance of Celtikci district belonging to the TECS was investigated by implementing a new proposed methodology. According to the performance analysis of the system, it was found that system has maximum 2 seconds error limit and its performance was found appropriate for all conditions (green to red, red to green, all green and all red). This study also demonstrated that the new measurement method accurately measures the performance of the system by examining all measurement possibilities.
\end{abstract}

Keywords: Traffic electronic monitoring systems, signalized intersection, red light violation detection, intelligent transportation systems.

\section{Introduction}

Traffic accidents at signalized and unsignalized intersections have an important percentage among the all traffic accidents in Turkey based on the official accident statistics [1,2]. This phenomena can easily be provided based on the traffic accident statistics with the spatial distribution data for the last five years as shown in Table 1 [3-7].

Table 1. Statistics of traffic accidents and their spatial distribution in the last 5 years in Turkey [3-7]

\begin{tabular}{cccc}
\hline Year & $\begin{array}{c}\text { The Number of } \\
\text { Total Accidents }\end{array}$ & $\begin{array}{c}\text { Number of Accidents } \\
\text { at Intersections (\%) }\end{array}$ & $\begin{array}{c}\text { Number of Accidents at Intersections } \\
\text { caused by red light violation (\%) }\end{array}$ \\
\hline 2011 & 1.228 .928 & $110.803(9.0 \%)$ & $3184(2.9 \%)$ \\
\hline 2012 & 1.296 .634 & $130.360(10.1 \%)$ & $3517(2.7 \%)$ \\
\hline 2013 & 1.207 .354 & $161.306(13.4 \%)$ & $3137(1.9 \%)$ \\
\hline 2014 & 1.199 .010 & $168.512(14.1 \%)$ & $3445(2.0 \%)$ \\
\hline 2015 & 1.313 .359 & $1830.11(13.9 \%)$ & $3967(2.2 \%)$ \\
\hline
\end{tabular}


When Table 1 is examined, it can be seen that the ratios of the traffic accidents at intersections have a fixed value over years and no significant decrease was observed. Many studies carried out around the world also indicated that the drivers are not disciplined in utilizing the lanes and speedy driving, red light violations were among the important problems affecting the traffic safety and increasing the road accidents [2, 8-10]. In their study, Coruh et al. [2]found that the fast rate of urbanization, along with increasing employment rates, places significant strain on have an important effect on traffic accidents for Turkey. Therefore, they suggested that Turkey needs to develop some countermeasures such as, well-designed road infrastructure networks across the country that is sustained over a long term. Also according to their study results, it was found that road-surveillance cameras strictly enforce speed limits and it was found that an increase in the number of red light traffic violations increases the number of accident counts significantly.

In recent years, intelligent transportation systems are under a continuous development which are the direct integration of the technology and traffic engineering aspects. These systems have capabilities of detecting the instantaneous and average speeds of vehicles along a roadway section, and red light violations. By the help of these sophisticated systems, road and security authorities can successfully carry out criminal sanctions against non-compliant drivers combined with plate reader cameras. One of the most applied places of these systems are signalized intersections where they are frequently used for detecting red light violations. The outcomes of the studies in many countries indicated that the vast majority of accidents that occurred at both signalized and unsignalized intersections were caused by the drivers who are not following the red light rule. To prevent the negative effect of red violations, red light violations detections systems are used in many countries (India, Turkey, USA, Iran, Brasil etc.) and in many intersection types (T, 4-leg, 3-leg, etc.) [11-15]. To examine and determine the effect of this system many studies were conducted by the researchers. For example, Baguley [16] observed that some drivers intentionally violate the red light and he reached the conclusion that to eliminate this problem, detection systems must be implemented. Yang and Najm [17] have found that these systems influence the behaviors of the drivers encountering the red lights, and especially they indicated that, warning plates placed at the intersections are helpful for taking the attention of the drivers. Yang and Najm [17] stated that, the average speed of the drivers passing during the red light state was $31.6 \mathrm{mph}$ and they added that $94 \%$ of the drivers made the violations 2 seconds after the red light state initiated and $2.7 \%$ of these drivers made the red light violation after 2 to 5 seconds after the initialization of the red light state. They also indicated that the drivers who violated the red lights were often elderly drivers (1.5 times more than young drivers) probably resulted by the weakening of the driver's perception with the age. Lum and Wong [18] considered a " $T$ " type intersection after installation of the red light violation system. They reported that red light violations were reduced to a value between 13.4 to 58.6 from 16 to 111.8 vehicles per day after the initialization of the system. In a similar study, Schattler et al. [19] investigated three intersections and stated that red light violations were reduced to 0 to 4.6 vehicles from 0 to 10.2 vehicles per hour with the installation of the red light violation detection systems. According to the Ruby and Hobeika [20], the installation of these systems reduced the red light violation cases to 0.17 to 7 vehicles per 10.000 cars from 2 to 11 vehicles. Fitzsimmons et al. [9] investigated the effects of these systems on the number of accidents that occurred at intersections. From the analyzes it was concluded that the total number of accidents at intersections was reduced by $44 \%$, the rear-front collisions were reduced by $40 \%$ and non rear-front collisions were reduced by $90 \%$. Considering these studies in literature, existing studies generally considered the effect of the red light violation detection system on violation numbers and accidents. Apart from that there is a serious concern in the literature about how to verify the accuracy of these systems (corresponding control methods) and how to determine the limit values or thresholds that drivers will not to be aggrieved. 
Within the scope of this study, the application of these systems has been focused on the reliability of detection of the red light violations and how to test these systems in manner of detection validity and performance. Particularly, the performance of a red light violation system installed at the 4-leg signalized intersection at Antalya-Burdur highway entrance of Çeltikçi district belonging to the TECS was investigated by implementing a new proposed methodology.

\section{Red Light Violation Detection Systems and Working Principles}

In Turkey, Traffic Electronic Control Systems, covered by TECS, are considered under different categories such as intelligent intersection systems, vehicle counting systems, safety strip violation detection systems, speed violation detection systems, speed corridors, red light violation detection systems and parking violation detection systems. These systems were implemented for sustaining a safe traffic flow by detecting the traffic rule violations and penalize the corresponding drivers to influence the driver's respect against the rules. Red Light Violation Detection Systems (KITS) is one of the most used systems of TECS in practice. KITS are developed with the aim of preventing accidents caused by red light violations at signalized intersections, detecting the offender drivers and applying criminal sanctions (See Figure 1).

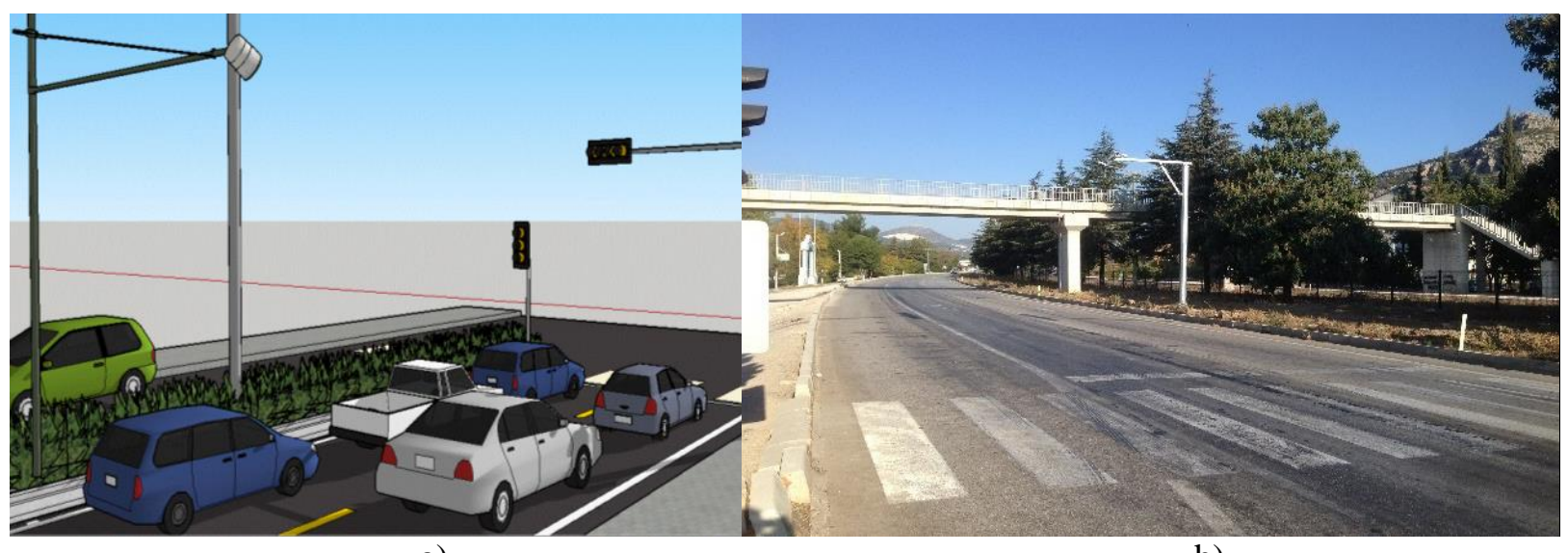

a)

b)

Fig.1. An example of a red light violation detection system (a) 3D design (b) real life application

The general characteristics of these systems can be summarized as follows [21-24]:

- System detects the traffic signal color by using a specialized detector device and receives the transmitted signal for evaluating the signal phase and the vehicle arrivals. All these parameters simultaneously evaluated together and reported to the recording unit so that the possibility of encountering an error is minimized.

- Violations are detected from backward-direction photographs that are taken afterwards the passage of a vehicle to provide the necessary evidence that the driver has violated the rules.

- The red color of the traffic signal transmitter is clearly displayed in the infringement picture.

- System can receive uninterrupted video recording for 24 hours.

- The authenticity of the images is guaranteed with the digital signature method for legal proof of the infringement images. 
- The digital camera technology used in the systems has the ability to take high-resolution serial images, multiple-lane violation detection feature, and the ability to detect all the violations that occur at the same time.

These systems use virtual loop creation and image analysis methods on the road to detect vehicles passing through red light. The system automatically identifies the plates of the infringing vehicles and transfers the information to the management software. The software can detect multiple violating vehicles at the same time thanks to the video analysis techniques and transmit all the images to the authorities belonging to the violation moment, before and after the violation. The software has the capability of detecting and reporting the drivers to the operator and the ticketing is performed automatically with the approval of the operator.

\section{General Information about the Examined Intersection}

Within the scope of the study, Red Light Violation Detection Systems applied to 4-leg signalized intersection located at "37.533823 30.482611" coordinates on the Antalya-Burdur highway were examined (Figure 2).

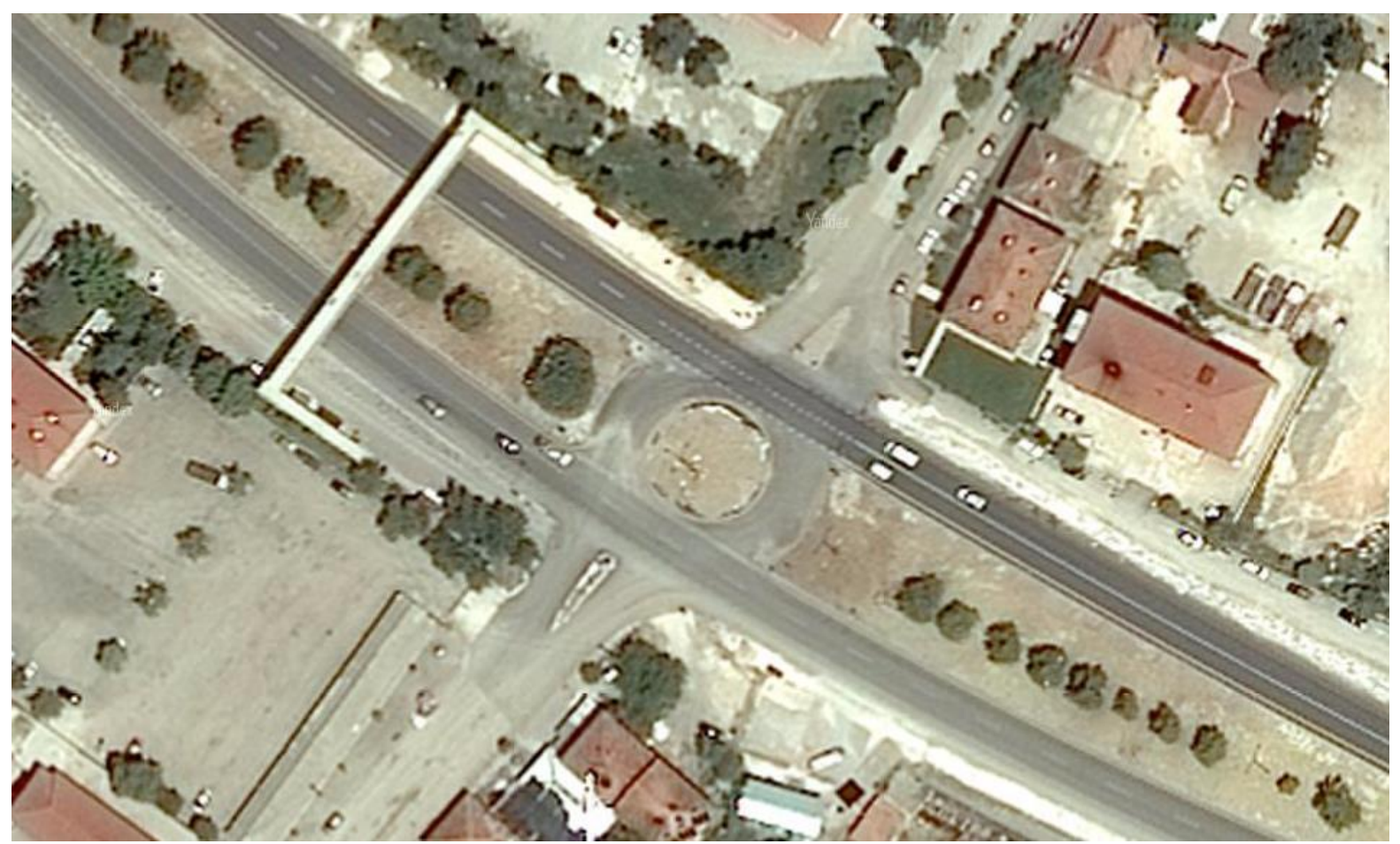

Fig.2. The corresponding intersection on the Antalya-Burdur highway Çeltikçi region, which is investigated for the red light violation detection system.

The investigation procedure was performed during the day light hours (06:30 am - 09:00 am) Different views from the investigated intersection is shown in Figure 3. 


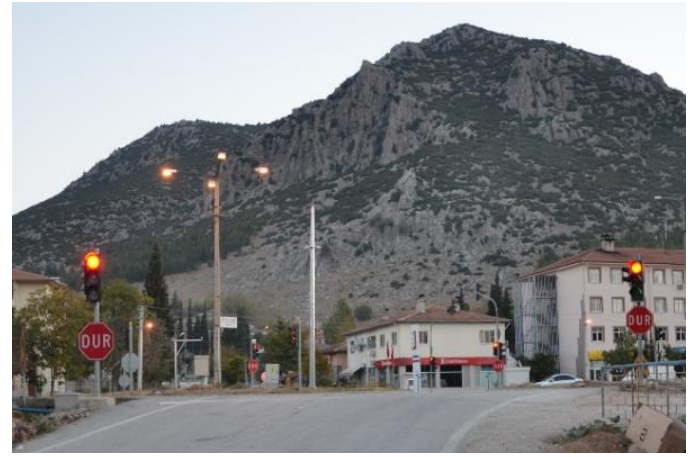

a)

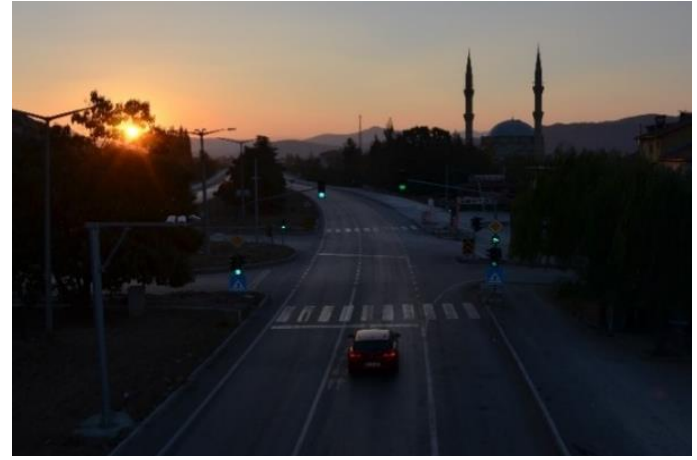

b)

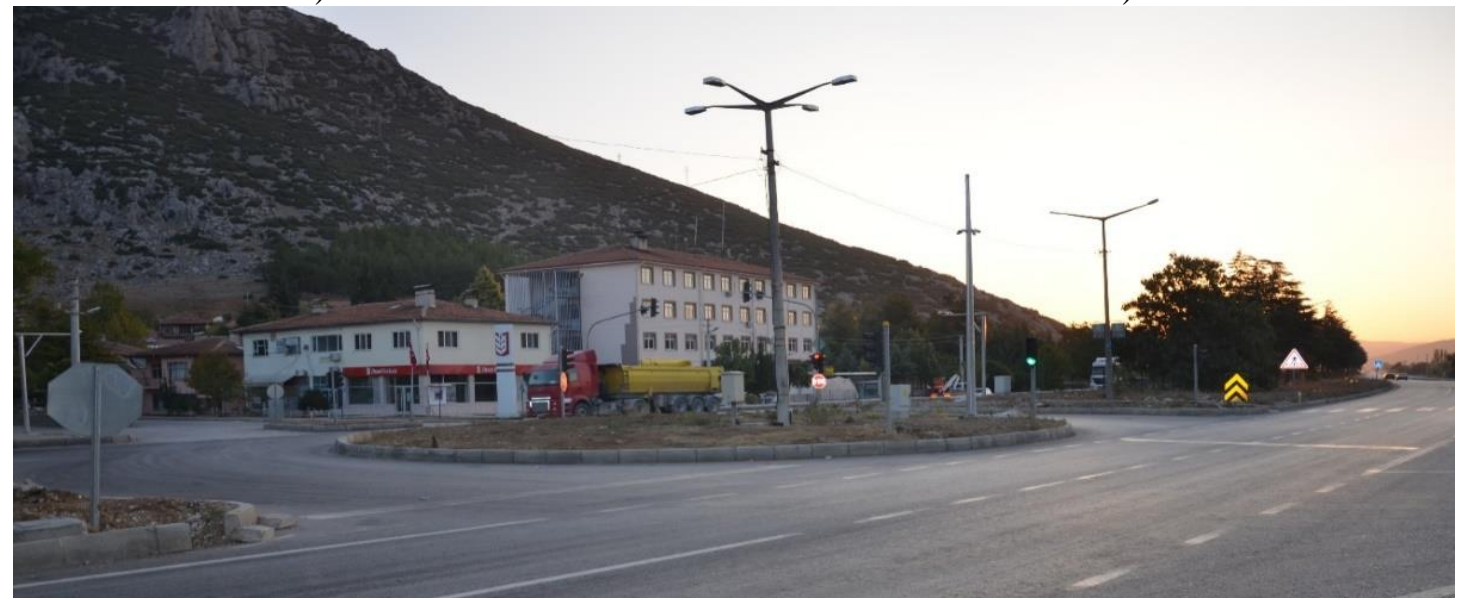

c)

Fig.3. Different views from the investigated intersection.

There are two important cases to be aware of when checking the reliability of the red light violation detection system. One of the case of the failure is that the system may ticket a vehicle which is not passing at the red light state and the second one is that the system may miss a vehicle which passes at the red light state. In the analyses, both of the case were considered by the investigation team by taking video recordings based on different vehicle approaching scenarios. For this eight different scenarios were prepared. The prepared study paper was shown in the Figure 4. According to these scenarios, the cases below were investigated.

- For the transition period from the red to the green and green to red light states, the passage of the vehicle 2-3 seconds after the red, yellow and green states were initialized.

The 2 to 3 delay seconds was considered to reflect the behaviors of the drivers under the influence of the dilemma zone who prefer to pass instead of stopping at the intersection. By this way, a safety factor methodology was added to the analysis results. 


\section{RED LIGHT VIOLATION DETECTION SYSTEM TEST WORKSHEET}

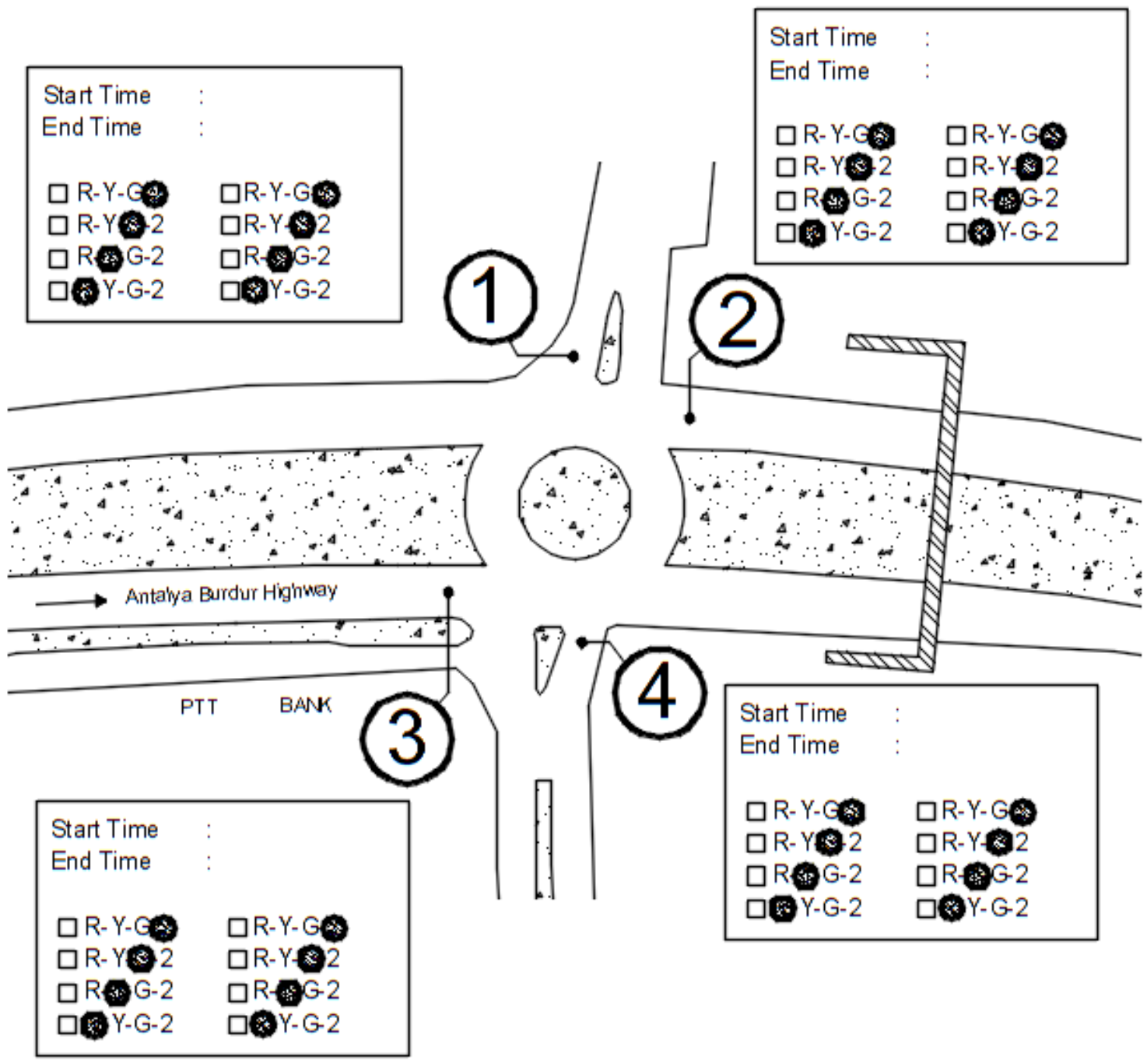

Fig. 4. A study paper prepared and used to test the performance of the examined red light violation detection system.

The data to be used within the scope of the study were collected by the researchers from the Akdeniz University with the help of field observations and video camera recordings made in October 2016. The video cameras which are positioned before the arms of the intersection were used to record the vehicle passing and the state of the traffic lights. For each intersection leg, a control vehicle was used with the coordination of the observers to provide safe and reliable investigation (See Figure 5). One of the researcher also registered if the provided scenario was successfully detected by the system or failed. The all investigation phase was completed in 20 minutes for each intersection by the researchers composed of three members. Not only the control vehicle but also the violations of the other vehicles were also recorded and considered in the study. 

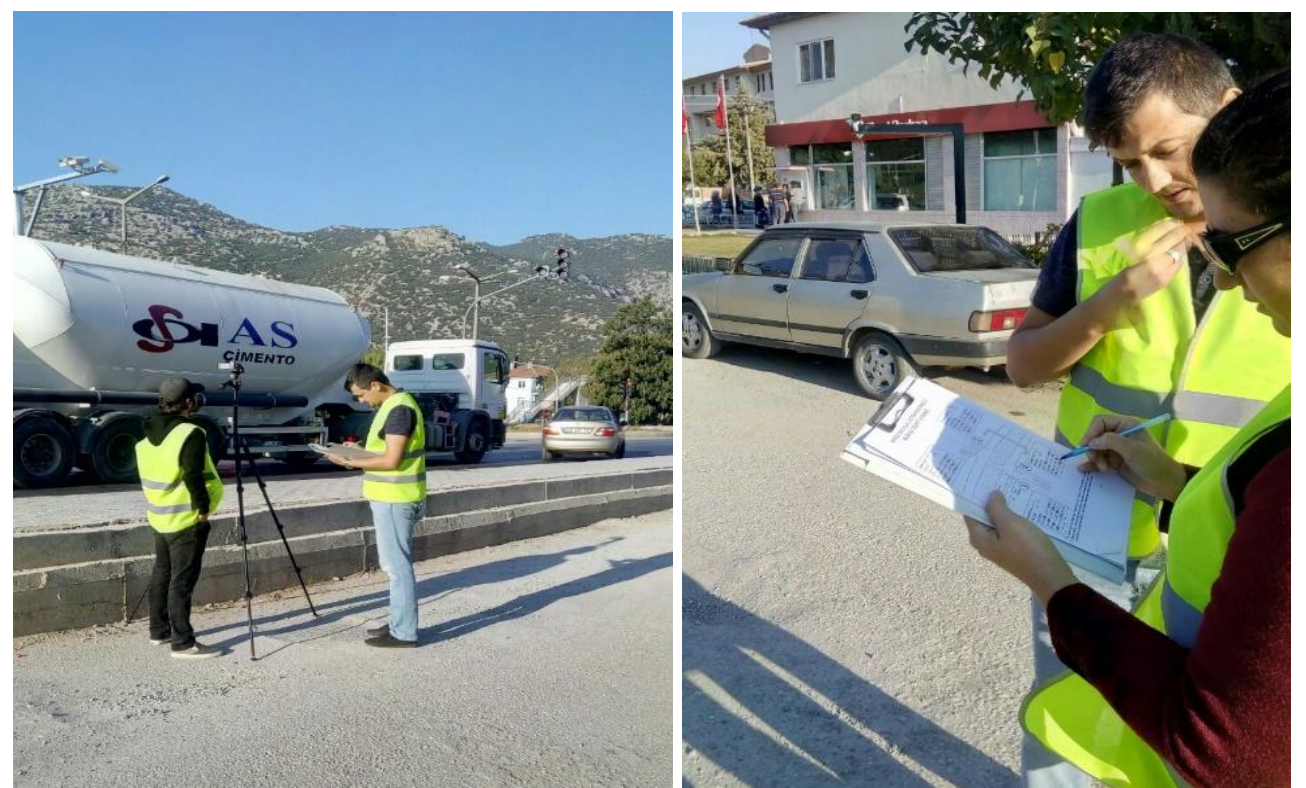

Fig.5. On-site control of the system.

\section{Investigation of the System and Findings}

The violations were transferred to a software under the control of the operator. In the Figure 6, the violations of the control vehicle and other drivers during the system testing period are shown in the control software.

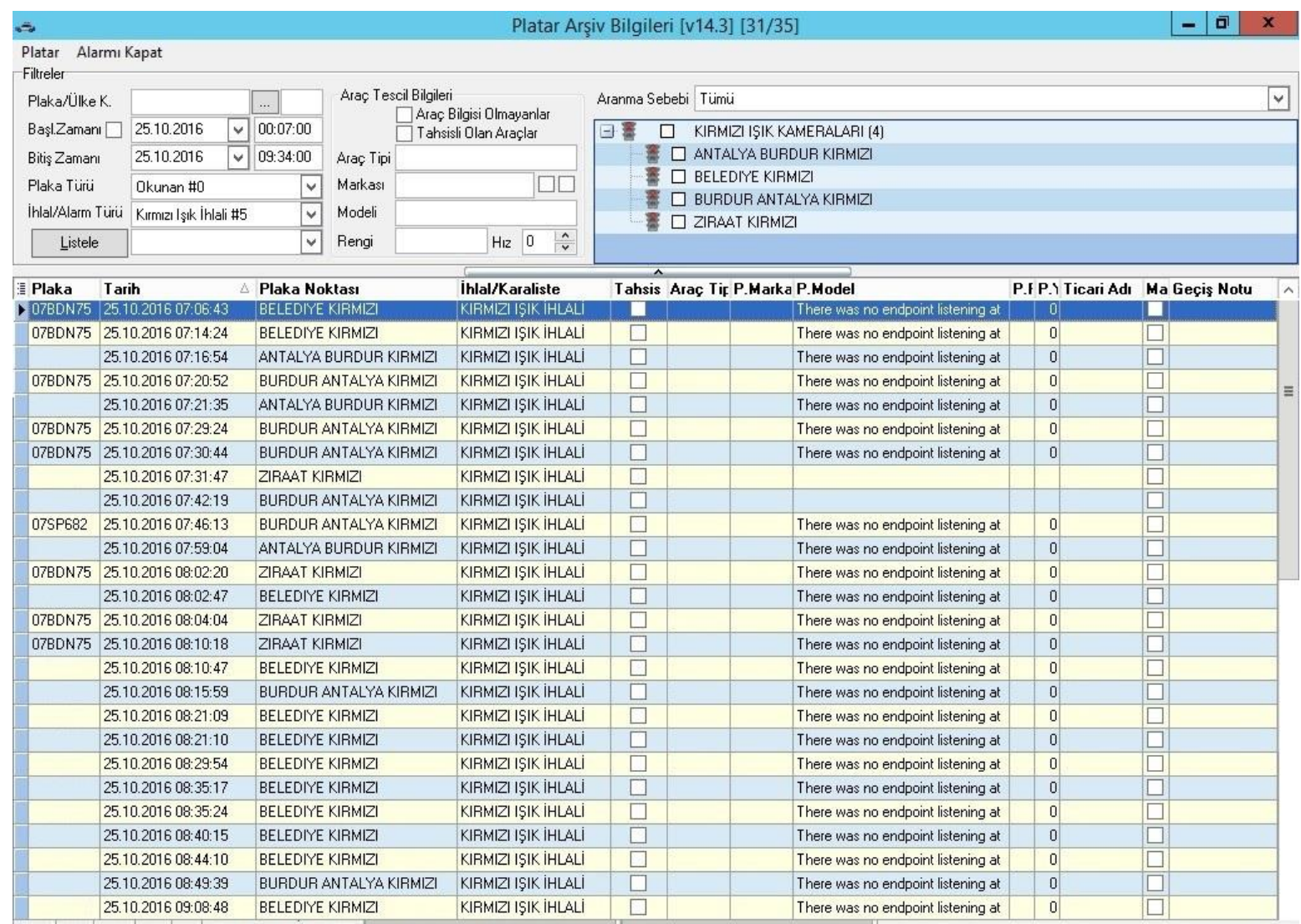

Fig.6. A view from the software with the listed red light violations. 
After the review of the software, the video recordings and field investigations were compared with the system output to check if the system works appropriate as shown in Figure 7.

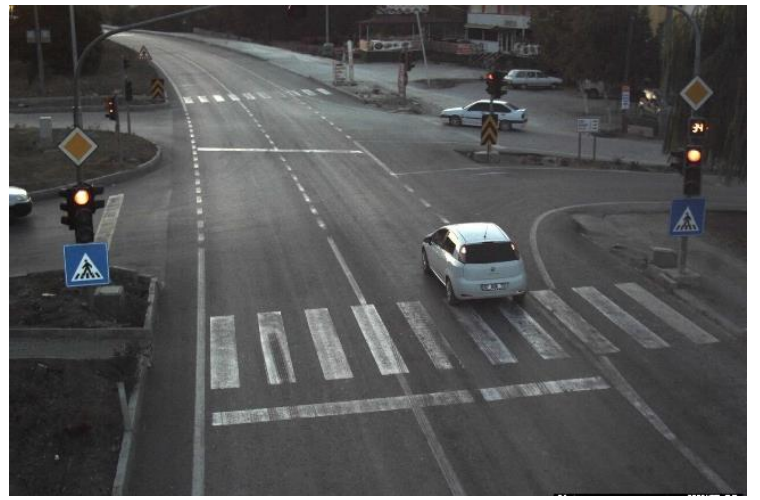

a)

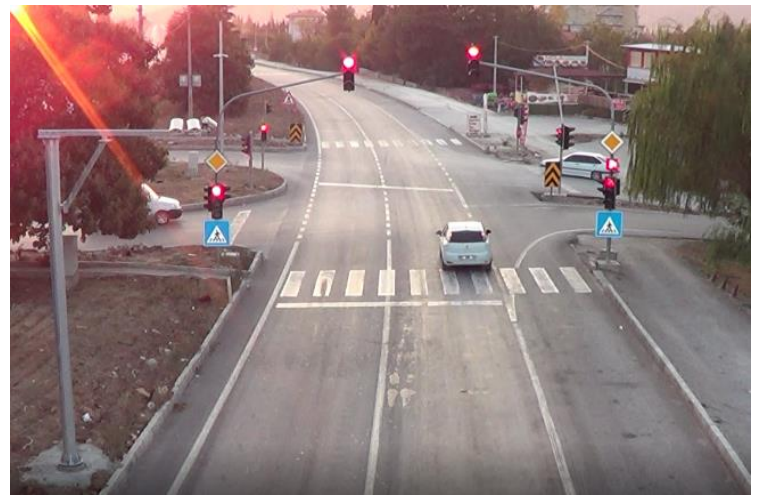

b)

Fig.7. The comparison of the red light violation detected (a) Red light violation detection system (b) researchers.

From the comparison of system and observation data, it was concluded that all the cameras of the red light violation detection system were properly working and all the violations were successfully detected by the applied system.

\section{Results and Conclusions}

It has been determined that devices belonging to the red light violation detection system, which are examined within the scope of the field observations, are actively working. From field observations and analyzes, it was concluded that eight different scenarios proposed to study the performance of each leg of a 4-leg signalized intersection were sufficient and efficient to examine the performance of red light violation detection systems. It has been determined that the violations determined by the system software and field tests give exactly the same results. In particular, none of the critical passing which would not be regarded as violations were not counted by the system. This shows that the system detects the violations in a reliable way. The system also correctly captured all of the passages not only during the transition between green to red but also red to green state of the traffic lights. It is important to note that this proposed investigation technique tries to consider the interests of the drivers and minimize or prevent unfairly traffic tickets. It was assumed that integrated detection systems for the signalized intersections considering the phase times will be developed and loop detectors will also be included to the detection systems in the future. For this reason, it is expected that our test methodology will be more prominent and developed by the implementation of these new generation systems.

\section{Acknowledgments}

The authors would like to thank Bilge Elektronik Güvenlik Bilgisayar Sistemleri ve İnşaat San. Tic. Ltd. Şti for their kindly help and support for the study. 


\section{References}

[1] Ghasemlou, K., Aydin, M., Yildirim, M., Prediction of pedal cyclists and pedestrian fatalities from total monthly accidents and registered private car numbers. Archives of Transport, 34(2), 29--35, 2015

[2] Coruh, E., Bilgic, A., Tortum, A., Accident analysis with aggregated data: The random parameters negative binomial panel count data model. Analytic methods in accident research, 7, 37-49, 2015.

[3] KGM, Trafik Kazaları Özeti 2011. 2011, Trafik Güvenliği Dairesi Başkanlığı: Ankara.

[4] KGM, Trafik Kazaları Özeti 2012. 2012, Trafik Güvenliği Dairesi Başkanlığı: Ankara.

[5] KGM, Trafik Kazaları Özeti 2013. 2013, Trafik Güvenliği Dairesi Başkanlığı: Ankara.

[6] KGM, Trafik Kazaları Özeti 2014. 2014, Trafik Güvenliği Dairesi Başkanlığı: Ankara.

[7] KGM, Trafik Kazaları Özeti 2015. 2015, Trafik Güvenliği Dairesi Başkanlığı: Ankara.

[8] Yung, N.H.C., Lai, A.H., An effective video analysis method for detecting red light runners. IEEE Transactions on Vehicular Technology, 50(4), 1074-1084, 2001.

[9] Fitzsimmons, E.J., The effectiveness of Iowa's automated red light running enforcement programs2007; ProQuest,2007.

[10] Günay, B., Erdemir, G., Lateral Analysis of Longitudinal Headways in Traffic Flow. International Journal of Engineering and Applied Sciences, 3, 90-100, 2011.

[11] Saha, S., Basu, S., Nasipuri, M., Basu, D.K., Development of an automated red light violation detection system (RLVDS) for Indian vehicles. arXiv preprint arXiv:1003.6052, 2010.

[12] Passetti, K., Hicks, T., Use of automated enforcement for red light violations. 1997, the University.

[13] Singh, H., Singh, S.J., Singh, R.P., Red Light Violation Detection Using RFID. Proceedings of 'I-Society, 2012.

[14] Heidari, M., Monadjemi, S.A., Effective Video Analysis for Red Light Violation Detection. Journal of Basic and Applied Scientific Research, 3(1s), 642-646, 2013.

[15] Brasil, R.H., Machado, A.M.C., Automatic Detection of Red Light Running Using Vehicular Cameras. IEEE Latin America Transactions, 15(1), 81-86, 2017.

[16] Baguley, C., 'Running the red'at signals on high-speed roads. Traffic engineering and control, 29(7-8), 415-420, 1988.

[17] Yang, C., Najm, W.G., Analysis of red light violation data collected from intersections equipped with red light photo enforcement cameras. 2006.

[18] Lum, K., Wong, Y., Impacts of red light camera on violation characteristics. Journal of transportation engineering, 129(6), 648-656, 2003.

[19] Schattler, K., Hill, C., Datta, T. Clearance interval design and red light violations.Today's Transportation Challenge: Meeting Our Customer's Expectations, Year.

[20] Ruby, D.E., Hobeika, A.G., Assessment of red light running cameras in Fairfax County, Virginia. Transportation Quarterly, 57(3), 33-48, 2003.

[21] Chin, H.C., Haque, M., Effectiveness of red light cameras on the right-angle crash involvement of motorcycles. Journal of advanced transportation, 46(1), 54-66, 2012. 
[22] Shin, K., Washington, S., The impact of red light cameras on safety in Arizona. Accident Analysis \& Prevention, 39(6), 1212-1221, 2007.

[23] Malone, B., Suggett, J., Stewart, D. Evaluation of the red light camera enforcement pilot project.ITE 2005 Annual Meeting and Exhibit Compendium of Technical Papers, Year.

[24] Burkey, M.L., Obeng, K., A detailed investigation of crash risk reduction resulting from red light cameras in small urban areas. 2004. 